\title{
SLLongwoods Review
}

Volume 4, Number $3 \bullet 2006$

\section{Editor-in-Chief}

Peggy Leatt, PhD

Editorial Advisory Board

Philip Berman

Director, European Health Management Association, Dublin, Ireland

Michael Guerriere, MD, MBA

Managing Partner, Courtyard Group, Toronto, ON

Peggy Leatt, PhD

Professor and Chair, Department of Health Policy and Administration, School of Public Health, University of North Carolina at Chapel Hill, Chapel Hill, NC

Cam Mustard, ScD

Professor, Department of Public Health Sciences

University of Toronto Faculty of Medicine

President/Scientific Director, Institute for Work

\& Health, Toronto, ON

Dorothy Pringle, PhD

Professor and Dean Emeritus, Faculty of Nursing, University of Toronto, Toronto, ON

Enrique Ruelas, $\mathrm{PhD}$

Senior Undersecretary, Mexico Health, Mexico City, Mexico

Eugene Schneller, PhD

Professor and Director, School of Health Administration \&

Policy, Arizona State University, Tempe, AZ

\section{Executive Editor}

Dianne Foster-Kent

E-mail: dkent@longwoods.com

Publisher

W. Anton Hart

E-mail: ahart@longwoods.com

Associate Publisher/Administration

Barbara Marshall

E-mail: bmarshall@longwoods.com

Associate Publisher/Media

Susan Hale

E-mail: shale@longwoods.com

Director, Design and Production

Yvonne Koo

E-mail:ykoo@longwoods.com

Graphic Designer, Design and Production

Jonathan Whitehead

E-mail: jwhitehead@longwoods.com

\section{Copy Editors}

James Gladstone, Wayne Herrington

Information contained in this publication has been compiled from sources believed to be reliable. While every effort has been made to ensure accuracy and completeness, these are not guaranteed. The views and opinions expressed are those of the individual contributors and do not necessarily represent an official opinion of Longwoods Review or Longwoods Publishing Corporation. Readers are urged to consult their professional advisors prior to acting on the basis of material in this journal.

No liability for this journal's content shall be incurred by Longwoods Publishing Corporation, the editors, the editorial advisory board or any contributors.

Longwoods Review is published quarterly by Longwoods Publishing Corp., 260 Adelaide St. East, No. 8, Toronto, ON Canada, M5A 1N1. Tel: 416-864-9667 Fax: 416-368-4443 ISSN 1708-0487

Canada Post Publications Agreement No. 40069375

(C) September 2006

\section{Strategies and Tools for Engaging the Broader Community in the Work of LHIN Boards: Lessons from Other Jurisdictions}

\author{
Maureen A. Quigley and Beverley J. Nickoloff
}

\section{INTRODUCTION}

While there is an opportunity to learn and build on experiences in other Canadian jurisdictions, Local Health Integration Networks in Ontario (LHINs) differ in a fundamental and important way from Regional Health Boards (RHBs) in other jurisdictions. Whereas other jurisdictions dissolved most provider boards and "integrated" them directly into the regional structure, LHINs have been established without dismantling the traditional power or governance structures (within or outside the Ministry of Health and Long-Term Care). Furthermore, a clear decision was made in Ontario to maintain voluntary, independent governance for all provider organizations, including hospitals, longterm care facilities, community health and support services, and mental health service providers.

The 14 LHINs are completing their first year of operation, in which they have been actively engaged in getting to know their communities and developing their first Integrated Health Services
Plan (IHSP) for their catchment area. The Local Health System Integration Act, 2006 (Section 16) states that "a local health integration network shall engage the community of diverse persons and entities involved with the local health system about that system on an ongoing basis, including about the integrated health services plan and while setting priorities." This legislated requirement has created a new dynamic in Ontario's healthcare landscape. The challenge currently being faced by all LHIN Boards is how to ensure appropriate and effective involvement of healthcare providers and the public in their work. In fact, finding the "right" mechanisms to engage with stakeholders - both individually and at an intersectoral level - and to obtain meaningful input as a result of this engagement is essential to ensuring not only effective decisionmaking of these Boards, but also, their very legitimacy. As they embark on their journey to integrate health services at the local level, there are some important questions to be asked by LHIN Boards:
1 Local Health System Integration Act, 2006, Section 16(1). On March 28, 2006, the Local Health System Integration Act (LHSIA) was presented to the Lieutenant Governor in Council and received Royal Assent. The ministry is currently developing the regulations and operational policy needed to support the implementation process. 
- Have Regional Health Boards (RHBs) in other provinces found effective ways to engage intersectoral involvement of providers in their work?

- What kind of investment is required to develop effective communication processes that will create opportunities for networking and exchange between LHIN Boards and providers/public?

- What can Ontario learn from the experiences of others?

\section{THE NEED FOR ENGAGEMENT}

A key goal underpinning the establishment of LHINs is to improve the coordination and integration of the system of health service delivery at the local level. Successful community engagement (i.e., provider and public participation) is seen by the government and the LHINs as essential for realizing this goal. Initially, engagement strategies have been implemented to support LHINs in the development of their Integrated Health Services Plan (IHSP) that will identify priorities for health services integration within each LHIN. Subsequently, in the implementation phase of the IHSP, engagement will be critical to build support for the steps required to close the gap between the LHINs' defined priorities and the current organization of services.

"Workable" strategies and tools are needed to initiate and sustain dialogue between Boards and providers and the public. Mechanisms developed will need to be open to those who have immediate interests in healthcare reform (e.g., healthcare providers, healthcare managers, patients) and those who have more diffuse interests and are distant from the day-to-day activities (e.g., citizens, taxpayers) (see Dubois 2004).

\section{WHAT CAN ONTARIO LEARN FROM OTHERS?}

While many jurisdictions across the country have devised a variety of structures and processes to "engage" providers (and the public) in their work, doing so effectively remains an ongoing challenge. (Table 1 provides a summary of some of the strategies and tools that have been used by RHBs in some provinces to build relationships with intersectoral provider groups.)

Based on a cursory review of the literature and feedback received from individuals involved in the work of RHBs in other jurisdictions, some important themes can be identified regarding strategies and tools for building relationships between RHBs (i.e., at the governance level, as opposed to management level) and intersectoral groups of providers.

\section{RATIONALE/OBJECTIVES FOR ENGAGEMENT OF STAKEHOLDERS}

1. The strategies and tools (i.e., structures and processes) used by RHBs to engage stakeholders in their work have been dependent on their objectives for consultation/input. The most common objectives for soliciting involvement arise from the need for RHBs to

- strengthen involvement of key "system" leaders in the work of their Board (sometimes in response to expectations included in Legislation/ Regulations)

- provide forums for broader consultation and an expanded level of input into the work of the regional "entity"

- involve the broader community in identifying needs and setting priorities to make healthcare planning and decision-making more responsive to population needs

- solicit advice on specific issues/ proposed changes

- improve coordination and integration of services (particularly primary health services with other parts of the health system)
- build an understanding of service changes that could impact a community

- demonstrate the organization's accountability to the public

- manage public expectations

- promote shared ownership of the work of the RHBs in their role as a successful "manager, coordinator and/or integrator" of health services.

\section{STRATEGIES AND TOOLS USED BY RHBS TO ENGAGE STAKEHOLDERS}

2. There has been significant variation in the types of strategies and tools used by RHBs to liaise/interact with intersectoral provider groups (and the public) both within and across jurisdictions. Some of the most common structures/processes have included

- consultations/focus groups

- community advisory groups

- public board meetings

- open forums

- annual reports

- representation of community/ provider members on Board committees

- regular "customer" feedback surveys

- use of the media (i.e., open-line talk shows) (see Quigley and Nickoloff unpublished).

3. Some regions have relied more on the use of existing forums (formal and informal) in communities to share information and consult on health service issues.

4. Some regions have used "targeted" community consultation initiatives $^{2}$ utilizing a range and variety of approaches such as focus groups, public meetings/forums, stakeholderspecific interviews and written submissions. These consultations are used in situations where time

2 Key benefits: involve a high level of public participation; provide valuable information to inform strategic directions. Drawbacks: require significant time commitments from all involved; expensive 
and budget permit and the Board determines

- there is potential for a significant impact on health services in a community or a group of communities

- the proposed issue will impact the strategic direction of the health authority; and

- there is an opportunity to influence a decision.

Participants may include the general public, care providers and community leaders.

5. During their early days of regionalization, some provinces did not feel the urgency to achieve stakeholder involvement (or secure intersectoral collaboration across providers groups) because of the "exclusion" of many specialized services (i.e., cancer and mental health ${ }^{3}$ ) from the responsibility and control of RHBs.

6. In some provinces, regions have developed formal frameworks outlining processes for involving stakeholders in RHB activities. For example, the Calgary Health Region developed a Public Participation Framework. The Vancouver Island Health Authority published the VIHA Public Participation Framework. These frameworks help determine the level of participation being sought and are dependent on a variety of factors such as the degree of public interest, the complexity of the issue, the risks to the organization, the budget and timing. The various levels of public participation are shown in Figure 1.

\section{BEST PRACTICES IN ENGAGEMENT}

7. Experiences in other jurisdictions confirm that finding the "right" structure(s) to engage communities in the work of RHBs has been "helpful" but in and of itself is not sufficient to ensure horizontal integration. Two key challenges that have arisen in engaging communities in promoting stronger integration across sectors have included

- ensuring that health services communities don't "wander" from health authority priorities and strategic directions

- developing expertise and resources in community development and relationship building as a primary role for RHB administrators (see Light).

8. The Quebec Regional Agency is an interesting and new model. The system is being "heavily managed" with hospitals negotiating/bidding to do specific volumes of activity based on tight targets that have been established in key areas (e.g., cancer surgery, radiation therapy, hip/knee surgery, day surgery/day procedures, cataracts). Monthly reports are provided to the [regional] Agency. Providers know what is expected and are held responsible and accountable for reporting on volumes (through monthly reports and quarterly meetings). These efforts are resulting in balanced budgets.

\section{CHALLENGES AND LIMITATIONS}

9. In some Canadian jurisdictions, stakeholders feel they have had less input into the healthcare system in their area since hospitals came under the governance of RHBs. In Nova Scotia, for example, a Minister's Task Force on Regionalized Health Care (Government of Nova Scotia 1999), which was mandated to analyze the current state of regionalization and to study its strengths and weaknesses, found that

- there is a general perception that community representation at the regional level is inadequate

- regionalization is widely misunderstood, with both providers and consumers believing that its main goal has been to cut costs

- deficiencies such as physician and nurse shortages, bed reductions and long waiting times have been attributed to regionalization.

Figure 1. Public participation approach to community consultation

\begin{tabular}{|c|c|c|}
\hline HIGH & $\begin{array}{l}\text { EMPOWER } \\
\text { e.g., Citizen Juries }\end{array}$ & LOW \\
\hline \multirow{4}{*}{ 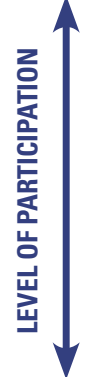 } & $\begin{array}{l}\text { COLLABORATE } \\
\text { e.g., Joint Task Forces }\end{array}$ & \multirow{4}{*}{$\begin{array}{l}\text { 을 } \\
\text { 을 } \\
\text { 罗 }\end{array}$} \\
\hline & $\begin{array}{l}\text { INVOLVE } \\
\text { e.g., Open Space }\end{array}$ & \\
\hline & $\begin{array}{l}\text { CONSULT } \\
\text { e.g., Survey \& Polls }\end{array}$ & \\
\hline & $\begin{array}{l}\text { INFORM } \\
\text { e.g., Public Meetings \& Open Houses }\end{array}$ & \\
\hline LOW & CONSULTATION GOALS & HIGH \\
\hline
\end{tabular}

Source: Public Participation Framework for the Vancouver Island Health Authority (VIHA). Vancouver Island Health Authority (August 2003) 
Table 1. A review of provincial strategies and tools supporting stakeholder engagement

\begin{tabular}{|l|l}
\hline British Columbia & $\begin{array}{l}\text { Public Meetings } \\
\text { - These meetings have been a "minimal requirement" for B.C. health boards. Meetings tend to be well attended, with } \\
\text { strong open debate. }\end{array}$ \\
$\begin{array}{l}\text { Governance Liaison Committees (also known as Community Leaders Forums) } \\
\text { - These committees provide a vehicle for liaising with local governance (board of education, the Mayor/municipal } \\
\text { politicians, police, parks and recreation, local MLAs and other community leaders) and are a way for Boards to make } \\
\text { local governance aware of their work/priorities, encourage dialogue on local and regional health issues and programs, } \\
\text { provide a forum to listen to concerns and plan mutual initiatives. }\end{array}$
\end{tabular}

\section{Community Health Advisory Committees (CHACs)}

- These committees have been established in the Vancouver Coastal Health Authority (as part of its community engagement process). These committees are advisory to the Executive team; however, activities are reported on through the Board Governance Committee. The purposes of the CHACs are to assist in establishing mechanisms for ensuring public input throughout the region as mandated by the Ministry of Health, and to achieve the goal of community engagement. These committees can meet anywhere from 4 to 10 times per year.

- CHACs provide a basis for developing strategies to address the health needs for specific populations. The first Health Advisory Committees focused upon Aboriginal health, seniors and adults with serious mental illness, and addictions populations.

\begin{tabular}{|c|c|}
\hline Alberta & $\begin{array}{l}\text { Engagement of Providers in work of RHBs } \\
\text { - In the early years of regionalization there was not a major focus at the RHA governance level on engaging providers/ } \\
\text { public in their work. In these years of intersectoral initiatives took place through the Provincial Health Authorities of } \\
\text { Alberta* (the body that replaced the Alberta Hospital Association in 1994-95). Or, they took place at the individual } \\
\text { program or service levels (i.e., the public health divisions of the RHAs did a lot of good work on injury prevention). } \\
\text { - With respect to other service sectors, the Calgary Health Region employs a number of vehicles. For example: } \\
\text { - Issue-specific coalitions (e.g., injury prevention, tobacco reduction (municipal by-law action), community } \\
\text { mobilization for physical activity. The health region often provides seed funding for joint projects, which usually } \\
\text { successfully leverages both in-kind and financial investments by other coalition members). } \\
\text { - Standing advisory committees which influence service design and policies in the member agencies' programs } \\
\text { (e.g., School Health with three school boards). } \\
\text { - Ad hoc working committees that review and rank applications in specific regional funding competitions (e.g., } 3 \\
\text { Cheers for the Early Years, a provincially funded, regionally managed initiative to support healthy early child devel- } \\
\text { opment). }\end{array}$ \\
\hline
\end{tabular}

\section{Public Participation in Decision-Making}

- Public Participation Framework developed by the Calgary Health Region and although considered a "best practice" has been used inconsistently (see Calgary Regional Health Authority 2000).

- The Alberta Health Authorities Act requires each authority to have at least one Health Council to assist with public interaction. At the time of regionalization, the Calgary Health Region satisfied this requirement with the Aboriginal Health Council, and achieved broader input on selected items through a variety of vehicles, including townhouse meetings, task-limited specific working groups (for example, access to urgent care services in the inner city after closure of the two downtown hospitals) and surveys.

- The Child and Women's Health Portfolio continues to have a long-standing Parent's Advisory Council, which provides input on matters related to the quality of care.

\begin{tabular}{l|l} 
Manitoba & District Health Advisory Councils
\end{tabular}

- Each RHA board may have up to four DHACs. The Councils are representative of a smaller geographic area within each of the RHAs and allow for grassroots input to the RHA board.

- RHA Boards determine the number of DHAC members and requirements for council membership.

\section{Advisory Committees}

- The DHACs recommended that healthcare providers, due to a potential for conflict of interest, should not qualify for RHA board membership. Therefore, each RHA Board must put in place at least one Multidisciplinary Provider Advisory Committee. Other Advisory Committees may also be established to provide the board with expert input.

- RHBs were replaced with health authorities [referred to as Agencies** for the development of Health and Social Services].

- Planning is done at a regional system, with the system being actively managed.

- Agency Board members are appointed by the government with input from CEO.

- Role of the Board is to act in an oversight capacity ("check and balance") with CEO holding a significant level of authority. Committees of the Board include the Planning, Finance, Human Resources. 
Table 1. Continued

\begin{tabular}{|c|c|}
\hline Quebec & $\begin{array}{l}\text { Establishment of Agencies for the Development of Health and Social Services (cont'd) } \\
\text { - Role of the Board is to act in an oversight capacity ("check and balance") with CEO holding a significant level of } \\
\text { - authority. Committees of the Board include the Planning, Finance, Human Resources. } \\
\text { Board meetings are public. } \\
\text { Authority of Agency CEO } \\
\text { - The CEO is not hired by the Board but appointed by government through Order In Council (Deputy Minister status; } \\
\text { performance review undertaken directly with Minister). } \\
\text { - CEO has significant decision-making authority and is held responsible for the budget and distribution of funds in a } \\
\text { "managed way." } \\
\text { - Agency signs a contractual agreement with government based on set targets negotiated between Government and the } \\
\text { Agency (agreements articulate what can and cannot be delivered). } \\
\text { Interactions with Other Boards (i.e., Meetings Between Agency CEO and Provider CEOs) } \\
\text { - Montreal had 144 separate provider boards, } 120 \text { of which were merged into } 12 \text { Health \& Social Service Centres } \\
\text { (HSSCs). The CEO of the Agency has no legal authority over HSSCs but works closely with them. } \\
\text { - CEO of Agency deals with these Centres at a management level. } \\
\text { - Under legislation, the Agency Board has the responsibility to maintain a "Forum of the Population," which serves } \\
\text { as a consultative body to the Agency CEO and forwards recommendations to the Board. Members of this group are } \\
\text { named by the Board but used at the discretion of the CEO. } \\
\text { Institutional and Regional Councils } \\
\text { - Representation and consultation in Quebec is greatly aided by Councils (both institutional and regional). } \\
\text { Best Practices/Lessons Learned } \\
\text { - The Agency structure seems to be working (e.g., Montreal Agency presented a balanced budget two years in a row; } \\
\text { ER volumes monitored daily by teams; volumes predictable and managed; integrated planning being undertaken at a } \\
\text { regional level). }\end{array}$ \\
\hline Nova Scotia & $\begin{array}{l}\text { Consultation Mechanisms } \\
\text { - Public meetings and use of surveys and focus groups to solicit opinion from healthcare providers, healthcare admin- } \\
\text { istrators and managers, healthcare consumers and the general public. } \\
\text { - Request and analyze written submissions from advocacy and other groups, health professional organizations, health } \\
\text { boards and the general public. }\end{array}$ \\
\hline
\end{tabular}

10. Finding ways to go beyond the "traditional circle" of academic and organizational experts has been a key challenge facing most regions in involving providers and/or the public in their work. Professionals tend to dominate the decision-making process, and research and past experience provide little supportive evidence that healthcare quality has been improved. These conclusions are based on a review of studies that conducted literature searches, provided expert opinion or presented results from surveys that researched participants' perceptions (see Zena Simces 2003).
11. "Restoring" the morale, involvement and support of the physician community has been a significant challenge confronting many RHBs. In B.C., for example, physicians reported that they were frustrated with the current regional funding system and were consistent in their lack of support for increased RHB influence over healthcare fund allocations and/ or physician payments (see British Columbia Medical Association 2003).

\section{EFFECTIVENESS OF STAKEHOLDER INVOLVEMENT}

12. Finding ways to engage providers and the public in the work of RHBs has been only part of the challenge. A bigger challenge has been to engage them in a decision-making process in a meaningful manner and in a way that is "comfortable" for them. Experience in other jurisdictions has found that citizens are willing to make decisions about principles, values, client satisfaction and to provide input related to service delivery, but are less willing to make decisions about planning and setting priorities, distributing funds and 
managing services (see Zena Simces 2003). In fact, as the complexity of devolved decision-making becomes clear, "the community" tends to favour assigning authority to traditional decision-makers (i.e., elected officials, experts and the provincial government) (see Abelson et al. 1995).

13. In local, national and international settings, the public (patient/patient groups) has contributed to the planning and development of healthcare services across a range of service areas and levels, but the impact of this involvement on the quality and effectiveness of health services is undetermined (see Abelson et al. 1995). Past experience, as reflected in the literature, suggests that there is no empirical evidence that the current mechanisms - boards of governance and advisory councils - adopted by governments to enhance citizen participation, accountability and responsiveness in healthcare decision-making are likely to be effective.

\section{CONCLUSION}

Given Ontario's unique approach to regionalization, it is difficult to find models from other jurisdictions that can provide guidance in achieving a collaborative governance relationship between LHINs and provider organizations. However, the variety of strategies and tools for community engagement used by RHBs in other Canadian jurisdictions, albeit executed largely at the operational levels, can assist LHIN Boards in determining approaches for engaging the community in their work and differentiating the respective roles of the LHIN Board, LHIN management and Provider Boards and management as part of the overall engagement process.

Based on the findings from other jurisdictions, the most significant challenges for LHINs in Ontario will be to undertake a process of community engagement which enables those who have input to be comfortable in their role within the decision-making process and to actually achieve value-added input to the LHIN in establishing and implementing the Integrated Health Services Plan.

During this first round of community engagement, LHINs have focused on soliciting general perspectives from the broad public and health service providers on what is important in terms of regional health service priorities. However, as the LHIN mandate evolves to actually setting priorities and allocating resources-based on these priorities, community engagement will need to take on a different focus in which LHINs shift their attention to "selling" (as opposed to soliciting) ideas for change and building support for their IHSPs both with provider organizations and the broader communities within their catchment areas.

Following the submission of their IHSPs to the Minister, it will be important for LHIN Boards to step back and assess the extent to which the processes used to engage the broader public and health service providers and the actual advice received have added value in their decisions on priorities for health services integration. Furthermore, as the approach to community engagement has varied across LHINs, it will also be important to share the learnings across LHINs to help refine subsequent processes for community engagement and to identify future target audiences.

\section{References}

Abelson, J., J. Lomas, J. Eyles, S. Birch and G. Veenstra. 1995 (August 14). "Does the Community Want Devolved Authority? Results of Deliberative Polling in Ontario." Canadian Medical Association Journal. 143(4): 421-42.

British Columbia Medical Association. 2003. Policy Papers - Regionalizing Health Care Budgets in BC. Retrieved July 21, 2006. <http://www.bcma.org/ public/news_publications/publications/ policy_papers/RegionalizingHealthCareBudge ts/ExecutiveSummary.asp $>$.

Calgary Regional Health Authority. 2000. Strengthening Community Action: Framework for Health and Wellness. Prepared by Bretta
Maloff and Yvette Penman, Calgary Regional Health Authority. Retrieved July 21, 2006. $<$ http://www.calgaryhealthregion.ca/hecomm/ comdev/pdf/SCAFrameworkFulldoc.pdfs.

Dubois, C.A. 2004 (November). Implementing Primary Healthcare Reform: Strategies to Align Stakeholder Support. Summary of the Discussions from a Seminar Organized by the Canadian Health Services Research Foundation's Primary Healthcare Network.

Government of Alberta. 1994. Regional Health Authorities Act.

Government of Nova Scotia. 1999 (July). Minister's Task Force on Regionalized Health

Care in Nova Scotia - Final Report and Recommendations.

Levine, D. 2005. "A Healthcare Revolution: Quebec's New Model of Healthcare." Healthcare Quarterly 8(4): 38-46.

Light, P. "Organizational Design and Integration: A Case Study of a Canadian Health Authority." Retrieved July 21, 2006. $<$ http://www.integratedcarenetwork.org/ publish/articles/000050/article_print.html>.

Ontario Ministry of Health and Long Term Care. Local Health System Integration Act, 2006.

Quigley, M. Collaborative Governance and Community Engagement. Presentation to the OHA Conference on Community Engagement, June 26, 2006.

Quigley, M. and B. Nickoloff. (unpublished). "Rethinking Regionalization: Can Regionalization Assist in Addressing the Challenges Facing the Ontario Health Care System?" Background paper prepared for the Ontario Ministry of Health and Long-Term Care.

Quigley, M. and G. Scott. Building Collaborative Governance with LHINs: Setting the Framework for a Collaborative Governance Model. Presentation at the OHA Conference on Local Health Integration Networks, April 28, 2005.

Quigley, M. and G. Scott. Advancing Collaborative Governance: A Potential Framework. Presentation to Local Health Integration Network Board Chairs, February 22, 2006

Vancouver Island Health Authority. 2003 (August). Public Participation Framework for the Vancouver Island Health Authority (VIHA).

Zena Simces \& Associates. 2003 (May 27). Exploring the Link Between Public Involvement/ Citizen Engagement and Quality Health Care - A Review and Analysis of the Current Literature. Prepared for Health Human Resources Strategies Division Health Canada. Retrieved July 21, 2006. <http://www. hc-sc.gc.ca/hcs-sss/pubs/care-soins/2003qual-simces/2003-qual-simces-1_e.html>. 


\section{Acknowledgments}

An initial version of this paper was prepared for the Chairs of the LHIN Boards in February 2006. The authors would like to acknowledge the following individuals who shared their perspectives on "engagement" in a regional health system: Ann Casebeer, Associate Professor, Health Sciences - Centre for Health and Policy Studies, Community Health Sciences, University of Calgary; Janet Davidson, Chief Operating Officer, Vancouver Coastal Health Authority Formerly, Assistant Deputy Minister of Health for the Province of Alberta; David Levine, CEO, Montreal Health Authority (Agency for the Development of Health and Social Services); Hume Martin, President \& CEO, Rouge Valley Health System (Formerly, Chief Regional Officer with the Calgary Health Region and Executive Director of the Alberta Children's Hospital); Richard Musto, Deputy Medical Officer of Health, Calgary Health Region; Hugh Scott, President \& CEO, The Scarborough Hospital (Formerly, Executive Director of the McGill University Health Centre).

The views expressed as well as any errors in the manuscript are those of the authors.

\section{About the Authors \\ Maureen Quigley, of Maureen Quigley \& Associates Inc., specializes in the facilitation of planning and change management processes in the Canadian healthcare sector. As part of her practice in health sector governance, she advises LHINs and health service providers on collaborative governance relationships and facilitates dialogue between LHIN and provider Boards of Directors.}

Beverley J. Nickoloff is an independent consultant. She has extensive experience in policy and program development, strategic planning and network development in the healthcare sector.

Corresponding Author:

Beverley J. Nickoloff, BA (Hon), BEd, MHSc

90 Roslin Avenue, Toronto, Ontario, M4N 1Z2, Phone: 416-484-4523, E-mail: bev.nickoloff@sympatico.ca

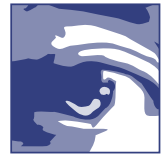

COMMENTARY

\title{
Engaging, Enabling and Empowering People for Health
}

\author{
Ken Morrison and Hy Eliasoph
}

\section{LHINS: A MADE-IN-ONTARIO APPROACH}

The creation of LHINs, a made-inOntario approach, is, in part, a response to the challenges and limitations faced by Regional Health Authorities (RHAs) across Canada in engaging the broader community. Simply stated, the LHIN model is unique in Canada insofar as it attempts to capitalize on the strengths of voluntary local governance. Unlike RHAs, LHINs were designed to work alongside, rather than replace, health services providers, thereby creating a dynamic that is daunting on the one hand, yet rife with potential on the other hand.

Why this is so fundamentally different is that LHINs, in endeavouring to engage their communities, have the distinct advantage of drawing on, and enlisting the help of, the health service providers, including hospitals, long-term care homes, mental health and addictions agencies, and community support service organizations. In contrast, RHAs have undertaken community engagement on their own, and in the absence of the support and involvement of health services provid- ers. For LHINs, working alongside providers could be a huge asset in that each of these providers has a governance structure, leadership team and frontpline staff that are potentially invested and grounded in their communities and the constituents they serve.

This is particularly true of the boards of many providers, in which voluntary local governance is characterized by a combination of individuals who bring both professional credentials and personal commitments to their responsibilities as governors. If "co-opted" to facilitate the engagement of their communities in the mission and activities of the LHIN, these providers could be a differentiating factor in successful engagement of the broader community/public.

Conversely, LHINs have a major challenge in first engaging the health service providers before successfully and effectively enlisting them in engaging the broader community. Convincing these providers that the LHIN is enabling rather than limiting could be a key "tipping point" in earning their support, and to help LHINs in engaging their collective communities. 


\section{THE CENTRAL LHIN - STAKEHOLDER ENGAGEMENT STRATEGY}

The Central LHIN, along with other LHINs has recognized that engagement extends to all providers and communities. Our Stakeholder Engagement Strategy, validated and subsequently released in Winter 2006, identifies several principles of engagement, including transparent, timely, inclusive, appropriate, accessible, balanced and accountable.

The goals of the Central LHIN stakeholder engagement strategy are to

\section{- focus on the people who use health} services - by placing the user at the centre and engaging directly with those who are most knowledgeable about their experience and degree of satisfaction with healthcare services - the users themselves;

- enhance local accountability - by vesting accountability at the local level through providing direct opportunities for input into decision-making;

- balance priorities - by informing and engaging the public and fostering a shared sense of responsibility for achieving balance among competing priorities;

- develop system capacity and sustainability - with a belief that communities are the best source of knowledge about their own needs and their own solutions, and by drawing on this knowledge and capacity, to identify needs and gaps and help build sustainable, long-term solutions.

Our Stakeholder Engagement Strategy identifies and defines the spectrum of stakeholders, sets out the continuum of engagement methods and identifies multiple options for various approaches to engaging the spectrum of stakeholders. Our strategy can be best characterized as multifaceted; it based on the philosophy that many different methods and means are needed to meet and respond to the many different needs and abilities of our communities. As such, each of the five phases of our strategy employs specific approaches and techniques to engage different constituents.

Foundational to our Stakeholder Engagement Strategy are six key elements:

1. a geographical approach intended to make engagement as geographically accessible as possible for all residents and communities within the Central LHIN, built on existing population distribution and geographical realities of the LHIN;

2. the establishment of Regional Stakeholder Groups in each of the five geographical areas was instrumental in helping to identify and connect with the hundreds of community-based groups, organizations, affiliations and leaders;

3. the recognition of the need to engage Health Interest Groups, who typically have a particular or welldefined interest or focus;

4. the establishment of Governance Councils comprising Board Chairs of all the health service providers, meeting with the Central LHIN Board Chair and board members to discuss issues from a governance perspective;

5. multiple levels of engagement that accommodate varying degrees of interest and ability to participate, and provide flexibility for engaging stakeholders relative to the complexity of the issue; and

6.an evaluative component to measure the extent to which the engagement strategy is achieving its intended goals and outcomes.

\section{WHERE ARE WE (GOING)?}

The Central LHIN Stakeholder Engagement Strategy does not offer something new or unique relative to what is identified in the RHAs by Quigley and Nickoloff. What is new and unique is the situational context within which the various components of the strategy are being employed. The end result is a unique blend of strategies that emphasize two key differences between RHAs and LHINs, these being in the legislated LHIN mandate to engage the public and the need to both enlist and engage the many health providers who continue to operate as independent organizational entities.

The ultimate success of the madein-Ontario LHIN model will likely be determined by the ability of LHINs to leverage providers and enlist their cooperation, support and influence in engaging the broader community of stakeholders in general and the public in particular. The Governance Councils could play a key role because they reflect and enable the board-toboard agreements and relationships required under the legislation. These relationships are expected to yield both enhanced accountability and collaboration - concepts that usually compete, rather than align.

\section{About the Author}

Ken Morrison is the Board Chair and Hy Eliasoph is the CEO of the Central Local Health Integration Network (LHIN), an area encompassing north central Toronto (North York), York Region and South Simcoe, with 1.5 million residents. LHINs have responsibility for planning, coordinating and funding health services for hospitals, long term care homes and community services. For more information, please contact Hy Eliasoph at: Hy.Eliasoph@Ihins.on.ca. 